\title{
Analysis of Ergosterol in Single Kernel and Ground Grain by Gas Chromatography-Mass Spectrometry
}

\author{
Yanhong Dong,* Brian J. Steffenson, and Chester J. Mirocha \\ Department of Plant Pathology, University of Minnesota, St. Paul, Minnesota 55108
}

\begin{abstract}
A method for analyzing ergosterol in a single kernel and ground barley and wheat was developed using gas chromatography-mass spectrometry (GC-MS). Samples were saponified in methanolic $\mathrm{KOH}$. Ergosterol was extracted by "one step" hexane extraction and subsequently silylated by $\mathrm{N}$-trimethylsilylimidazole/trimethylchlorosilane (TMSI/TMCS) reagent at room temperature. The recoveries of ergosterol from ground barley were 96.6, 97.1, 97.1, 88.5, and $90.3 \%$ at the levels of $0.2,1,5,10$, and $20 \mu \mathrm{g} / \mathrm{g}(\mathrm{ppm})$, respectively. The recoveries from a single kernel were between 93.0 and $95.9 \%$. The precision (coefficient of variance) of the method was in the range $0.8-12.3 \%$. The method detection limit (MDL) and the method quantification limit (MQL) were 18.5 and $55.6 \mathrm{ng} / \mathrm{g}$ (ppb), respectively. The ergosterol analysis method developed can be used to handle 80 samples daily by one person, making it suitable for screening cereal cultivars for resistance to fungal infection. The ability for detecting low levels of ergosterol in a single kernel provides a tool to investigate early fungal invasion and to study mechanisms of resistance to fungal diseases.
\end{abstract}

KEYWORDS: Ergosterol; wheat; barley; single kernel; GC-MS

\section{INTRODUCTION}

Fusarium head blight (FHB), a fungal disease caused by various Fusarium species, has been a devastating disease for all classes of wheat and barley over the past decade in the U.S. (1). The disease caused yield reduction and lowered grain quality. Fusarium graminearium, the primary FHB pathogen in the U.S., produces harmful mycotoxins such as dexoxynivalenol (DON) that can contaminate grain leaving it unsuitable for human consumption and animal feed. The total economic impact from FHB was estimated at $\$ 7.7$ billion from 1991 to 2001 across nine states in the U.S. (2).

Ergosterol is the principal sterol of fungal cell membranes and is either absent or a minor constituent in higher plants (3, 4 ). It has been widely used as a chemical marker for measuring fungal biomass in airborne dust, building materials, soil, plant tissue, and grains (5-16). Ergosterol also has been used to investigate fungal invasion in grains $(4,17)$, study resistance mechanisms to FHB pathogens $(18,19)$, and explore the relationship between DON and fungal invasion for the purpose of predicting DON contamination in Fusarium-infected wheat (20).

Gas chromatography-mass spectrometry (GC-MS) was a method of choice for analyzing ergosterol in environmental samples such as airborne dust and building materials due to its high detection selectivity and sensitivity (6-9). On the other hand, high-performance liquid chromatography (HPLC) was most frequently used to analyze ergosterol in grain samples.

* To whom correspondence should be addressed. Tel: +1612 625 2751. Fax: +1612625 9728. E-mail: dongx001@umn.edu.
The method was first developed by Seitz et al. (17) about 30 years ago and further modified by others in subsequent studies $(14,16,21,22)$. Lamper et al. (20) described a GC-MS method of analyzing ergosterol in Fusarium-infected wheat, which is the only GC-MS method reported for the analysis of ergosterol in grain samples. No method validation was mentioned in the paper. Here, we present a systematic development of a quick, sensitive, and reliable method to quantify ergosterol in barley and wheat using GC-MS. The method can be used for quantifying ergosterol from both ground grain and a single kernel. To our knowledge, the feature of analyzing ergosterol in a single kernel has not been reported in the literature. The single kernel analysis can be used to investigate early fungal invasion, monitor fungal growth and study mechanisms of resistance to FHB and other fungal diseases in greenhouses and laboratories where materials are limited most of the time. The method can be easily applied to handling a large number of samples, making it suitable for screening cereals for FHB resistance.

\section{MATERIALS AND METHODS}

Chemicals. Ergosterol (purity: 98.6\%) and potassium hydroxide $(88.2 \%)$ were purchased from Sigma-Aldrich (St. Louis, MO). $\mathrm{N}$ Trimethylsilylimidazole (TMSI, 98\%) and trimethylchlorosilane (TMCS, 99.5\%) were purchased from Pierce (Rockford, IL). 1,1a,2,2,3,3a,4,5,5,5a,5b,6-Dodecachlorooctahydro-1,3,4-metheno- $2 H$-cyclobuta- $[c d]$ pentalene (Mirex, 99.9\%) was obtained from Supelco (St. Louis, MO). Hexane (a mixture of isomers, certified ACS) and HPLC grade chloroform, methanol, 2,2,4-trimethylpentane (isooctane), and water were obtained from Fisher Scientific (Pittsburgh, PA).

Sample Preparation. (i) Ground Sample. Wheat or barley samples were ground in a Stein Mill (model M-2, Fred Stein Laboratories Inc., 
Atchison, KS). The $200 \mathrm{mg}$ ground sample was placed in a $20 \mathrm{~mL}$ polyethylene vial with a white poly lined plastic cap. A $3 \mathrm{~mL}$ volume of $10 \% \mathrm{KOH} / \mathrm{MeOH}(\mathrm{w} / \mathrm{v})$ was added, and then the vial was shaken on a Precision reciprocal shaking water bath (Winchester, VA) at 80 ${ }^{\circ} \mathrm{C}$ for $60 \mathrm{~min}$. The cap was loosened to release internal pressure around $5 \mathrm{~min}$ after heating and then retightened. A $1 \mathrm{~mL}$ volume of water was added, and ergosterol was extracted with one $4 \mathrm{~mL}$ volume of hexane. A $2 \mathrm{~mL}$ amount of hexane extract (upper layer) was transferred to a 4 $\mathrm{mL}$ screw top vial and dried under nitrogen.

(ii) Single Kernel. A single kernel of wheat or barley was weighed and placed in a $20 \mathrm{~mL}$ polyethylene vial with a white poly lined plastic cap. A $2 \mathrm{~mL}$ amount of $5 \% \mathrm{KOH}(\mathrm{w} / \mathrm{v})$ in $\mathrm{MeOH} / \mathrm{H}_{2} \mathrm{O}(95 / 5$, v/v) was added, and the vial was shaken on a Precision reciprocal shaking water bath at $80^{\circ} \mathrm{C}$ for $6 \mathrm{~h}$ followed by shaking on an Eberbach reciprocal shaker (Ann Arbor, MI) at room temperature for $18 \mathrm{~h}$. The cap was loosened to release internal pressure around $5 \mathrm{~min}$ after heating and then retightened. A $0.5 \mathrm{~mL}$ volume of water was added, and one $3 \mathrm{~mL}$ volume of hexane was used to extract ergosterol. A $1.5 \mathrm{~mL}$ amount of hexane extract was transferred to a $2 \mathrm{~mL}$ screw top vial and dried under nitrogen.

Derivatization. (i) Ground Sample. A $50 \mu \mathrm{L}$ amount of TMS (trimethylsilyl) reagent $(\mathrm{TMSI} / \mathrm{TMCS}=100 / 1, \mathrm{v} / \mathrm{v})$ was added to a 4 $\mathrm{mL}$ vial containing dried extract. The vial was rotated to ensure that the TMS reagent was in contact with all of the extract in the vial. The vial was then shaken on an Eberbach shaker for 10 min. A $500 \mu \mathrm{L}$ volume of isooctane containing $400 \mathrm{ng} / \mathrm{mL}$ of Mirex was added and shaken gently, after which $500 \mu \mathrm{L}$ of water was added. The vial was shaken on a vortex mixer (Scientific Products, McGaw Park, IL) until a milky isooctane layer became transparent. The upper layer (isooctane layer) was transferred to a $\mathrm{GC}$ vial.

(ii) Single Kernel. A $25 \mu \mathrm{L}$ amount of TMS reagent (TMSI/TMCS $=100 / 1, \mathrm{v} / \mathrm{v}$ ) was added to a $2 \mathrm{~mL}$ vial containing dried extract. The vial was rotated to ensure that the TMS reagent was in contact with all of the extract in the vial. The vial was then shaken on an Eberbach shaker for $10 \mathrm{~min}$. A $150 \mu \mathrm{L}$ amount of isooctane containing $400 \mathrm{ng} /$ $\mathrm{mL}$ of Mirex was added and shaken gently, after which $150 \mu \mathrm{L}$ of water was added. The vial was shaken on a vortex mixer, and the clear upper isooctane layer was transferred to a $\mathrm{GC}$ vial with a $200 \mu \mathrm{L}$ glass insert.

Standard Curve Preparation. Hulls of mycotoxin-free barley seeds (cultivar Robust grown in Arizona) were removed by a small-scale pearling machine to produce ergosterol-free barley. A $10 \mathrm{~g}$ amount of ground ergosterol-free barley was saponified with $10 \% \mathrm{KOH} / \mathrm{MeOH}$ (w/v) at $80{ }^{\circ} \mathrm{C}$ and extracted with hexane as described above. A $2 \mathrm{~mL}$ volume of hexane extract was transferred to a $4 \mathrm{~mL}$ screw top vial and dried under nitrogen. These samples were later used as a barley matrix to prepare the ergosterol standard curve. A standard curve consisting of $0.025,0.05,0.1,0.25,0.5,1.0,2.5,5.0$, and $10.0 \mathrm{ng} / \mu \mathrm{L}$ of ergosterol was prepared by adding the appropriate amounts of $10 \mathrm{ng} / \mu \mathrm{L}$ ergosterol standard solution to the vial containing the barley matrix and derivatizing by the TMS reagent as described above.

Gas Chromatographic-Mass Spectrometric Analysis (GC-MS). All samples were analyzed on a Shimadzu GCMS-QP2010 (Shimadzu Corp., Kyoto, Japan) equipped with the AOC-20 auto sampler/auto injector. All data were processed using GCMSsolution software (version 2.10 Su2F). Perfluorotributylamine (PFTBA) was used to tune the mass spectrometer. A J\&W DB-5MS capillary column $(0.25 \mu \mathrm{m}$ film thickness, $0.25 \mathrm{~mm}$ i.d., and $29.5 \mathrm{~m}$ length after cutting $50 \mathrm{~cm}$ of the leading edge for column maintenance) was used to separate compounds. A high-pressure injection method $(300.0 \mathrm{kPa}, 1.00 \mathrm{~min})$ was used in the splitless injection system. Linear velocity of flow control mode was used with the following oven temperature program: $80{ }^{\circ} \mathrm{C}$ for 1 min and then $50{ }^{\circ} \mathrm{C} / \mathrm{min}$ to $300{ }^{\circ} \mathrm{C}$ holding $6 \mathrm{~min}$. Injection, ion source, and interface temperatures were kept at 290,220 , and $300{ }^{\circ} \mathrm{C}$, respectively. Injection volume was $1 \mu \mathrm{L}$. Ergosterol was detected using selected ion monitoring (SIM) mode with electron ionization energy of $70 \mathrm{eV}$. The fragment ions of $\mathrm{m} / \mathrm{z} 363,337$, and 468 were used for ergosterol quantitation. Concentrations of ergosterol in barley or wheat samples were calculated using a standard calibration curve generated with each set of samples. Mirex in each sample was used to monitor the stability or the precision of the instrument. A naturally Fusarium-

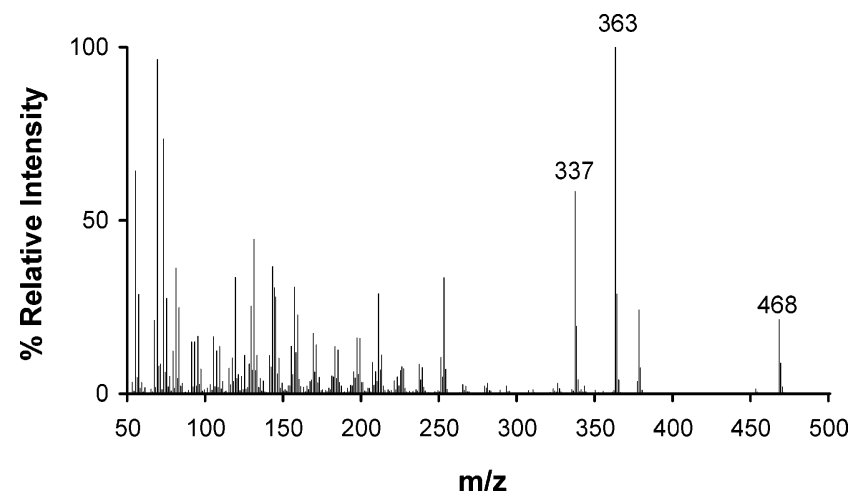

Figure 1. Mass spectrum of the TMS derivative of ergosterol.

infected wheat sample with a certain concentration of ergosterol was run with every 20 samples as a control to check the reproducibility of sample analysis.

\section{RESULTS AND DISCUSSION}

The mass spectrum of ergosterol-TMS derivative is shown in Figure 1. Fragment ions of $\mathrm{m} / \mathrm{z}, 337,363$, and 468 are three characteristic ions of ergosterol-TMS derivative. The peak at $\mathrm{m} / \mathrm{z} 468$ is from a molecular ion $\left(\mathrm{M}^{+}\right)$, and $\mathrm{m} / \mathrm{z} 363,[\mathrm{M}-105]^{+}$, is due to loss of the trimethylsilanol group and one methyl group. It was suggested that the $m / z 337,[\mathrm{M}-131]^{+}$, is produced by loss of the trimethylsilanol group and the $\mathrm{C}_{1}-\mathrm{C}_{3}$ fragment (6). However, the mass spectrum of deuterated ergosterol-TMS derivative ([4- $\left.{ }^{2} \mathrm{H}_{2}\right]$ ergosterol-TMS) indicated that the $\mathrm{m} / z, 337$ is produced by loss of the trimethylsilanol group and $\mathrm{C}_{2}-\mathrm{C}_{4}$ fragment (8). The $m / z 363$ is the most abundant fragment, so it was use as the target ion for ergosterol quantitation. The $\mathrm{m} / \mathrm{z}$ 337 and 468 fragments were used as reference ions, and the intensity ratios of $\mathrm{m} / \mathrm{z} 363 / 337$ and 363/483 together with the retention time were used to ensure the correct identification of ergosterol.

Figure 2 shows the standard curves for high and low concentration ranges of ergosterol. In general, a 9-point standard curve $(0.025-10 \mathrm{ng} / \mu \mathrm{L})$ was used to calculate ergosterol concentrations. A 6-point standard curve $(0.025-1.0 \mathrm{ng} / \mu \mathrm{L})$ was used to quantify concentrations of ergosterol lower than $1.0 \mathrm{ng} /$ $\mu \mathrm{L}$ to obtain better accuracy. Both calibration curves are quite linear with $R^{2}$ values of 0.999374 and 0.999587 , respectively. An ion chromatogram constructed from the sum of SIM signals is shown in Figure 3 for the TMS derivative of $5 \mathrm{ng} / \mu \mathrm{L}$ of ergosterol prepared in barley matrix. The peak with a retention time of 9.335 min came from ergosterol-TMS derivative. Mirex used to monitor the stability of the instrument was observed at $6.638 \mathrm{~min}$. The concentration of Mirex in each sample was the same, so the intensity of Mirex reflected the stability of the instrument or the precision of the instrument. Ergosterol-TMS standard solutions generated by reacting ergosterol with TMSI/ TMCS (100/1, v/v) silylating reagent at room temperature for $10 \mathrm{~min}$ and then extracted to isooctane were very stable as compared with freshly prepared standard solutions. The standard solutions can be used for at least 2 months by storing in a -20 ${ }^{\circ} \mathrm{C}$ freezer. The detection sensitivity for ergosterol derivatized by TMSI/TMCS is similar to that by $N, O$-bis(trimethylsilyl)trifluoroacetamide/pyridine (BSTFA/py) $(6,8,20)$. The TMSI/ TMCS derivatization method is, however, simple and more efficient than BSTFA since the latter requires longer derivatization time $(30 \mathrm{~min})$ and/or higher temperature $\left(60{ }^{\circ} \mathrm{C}\right)$. No column deterioration was observed in our study or in the study conducted by Nielsen et al. (8), a phenomenon experienced by 

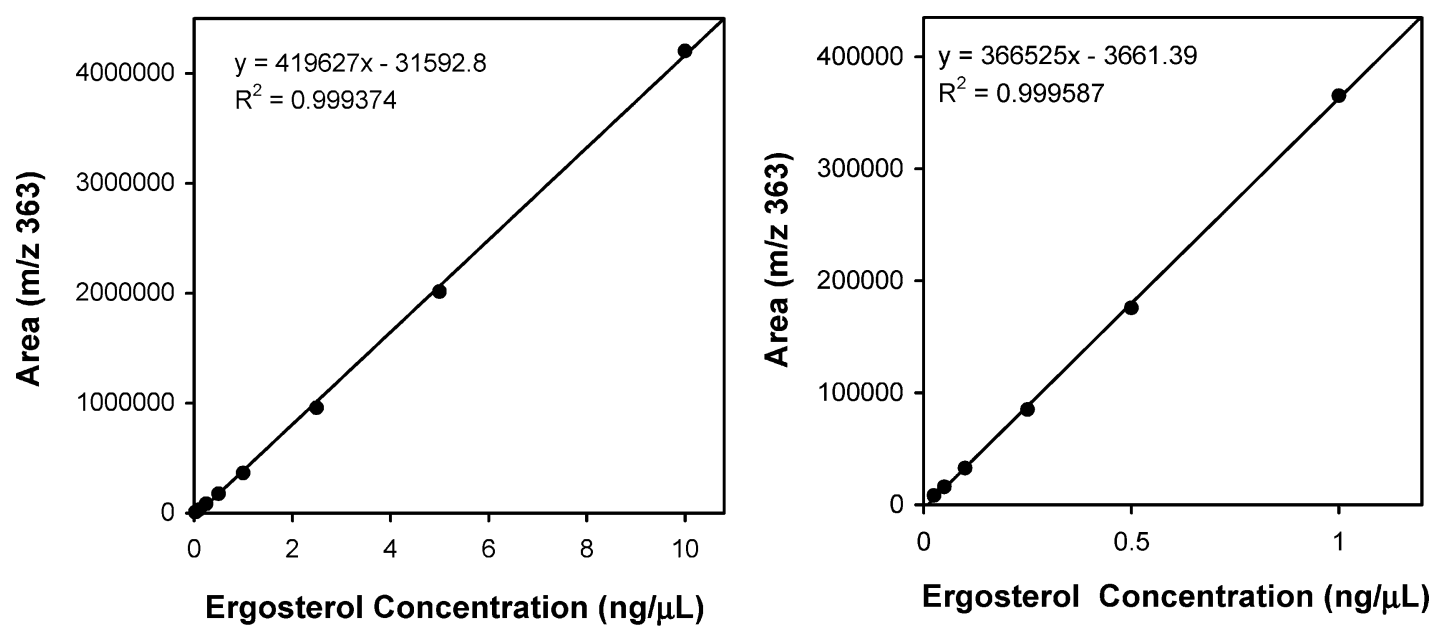

Figure 2. Standard calibration curves of ergosterol in the concentration ranges of $0.025-10 \mathrm{ng} / \mu \mathrm{L}$ (left) and $0.025-1.0 \mathrm{ng} / \mu \mathrm{L}$ (right) prepared in barley matrix.

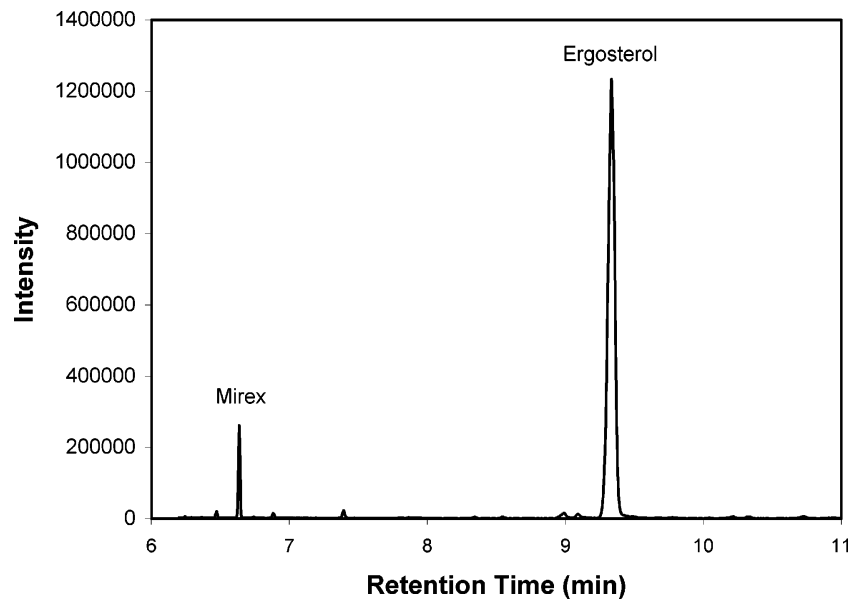

Figure 3. Ion chromatogram constructed from the SIM signal of $\mathrm{m} / \mathrm{z} 237$ (Mirex) between 6 and 9 min and the sum of SIM signals of $\mathrm{m} / \mathrm{z} 337$, 363 , and 468 (TMS derivative of $5 \mathrm{ng} / \mu \mathrm{L}$ of ergosterol prepared in barley matrix) between 9 and $11 \mathrm{~min}$.

Young (5). Nielsen et al. suggested that different injection mode (splitless injection vs on-column injection) might contribute to the different observations. In our case, we believe that $\mathrm{H}_{2} \mathrm{O}$ added prior to ergosterol extraction by hexane and before ergosterol-TMS extraction by isooctane plays an important role in preventing column deterioration. By addition of $\mathrm{H}_{2} \mathrm{O}$, the saponification reagent $\mathrm{KOH}$ that could damage the stationary phase of capillary column was prevented from entering the organic phase and further being injected onto the GC column.

Ergrosterol is partially bound as different esters in fungi (8). The esters can be hydrolyzed by $\mathrm{KOH}$ to release free ergosterol that can be extracted by methanol and hexane and analyzed by GC-MS. The ergosterol extraction efficiency was examined by extracting ergosterol from a ground wheat sample infected with Fusarium using the procedure described above at $80^{\circ} \mathrm{C}$ for 30 , 60,90 , and $120 \mathrm{~min}$, respectively. The ergosterol concentrations of $4.24,4.54,4.51$, and $4.78 \mu \mathrm{g} / \mathrm{g}$ were determined for the 30 , 60,90 , and 120 min extraction, respectively. The result showed that 60 min was sufficient for ergosterol extraction.

The barley seeds (cultivar Robust, Arizona) used for preparing the barley matrix were free of deoxynivalenol (DON) and its derivatives. They did, however, contain a low level of ergosterol $(0.2 \mu \mathrm{g} / \mathrm{g})$, indicating the existence of minor fungal infection. Ergosterol-free barley was obtained by removing its hulls using
Table 1. Percent Recovery of Ergosterol after Spiking Ergosterol-free Barley at the Levels of $0.2,1,5,10$, and $20 \mu \mathrm{g} / \mathrm{g}$

\begin{tabular}{ccrrrrr}
\hline & \multicolumn{5}{c}{ recovery (\%) } & \\
\cline { 2 - 5 } spiked levels $(\mu \mathrm{g} / \mathrm{g})$ & rep 1 $^{a}$ & rep 2 & rep 3a & mean & SD $^{b}$ & $\% \mathrm{CV}^{c}$ \\
\hline 0.2 & 96.9 & 99.9 & 92.9 & 96.6 & 3.51 & 3.6 \\
1 & 90.0 & 98.5 & 102.9 & 97.1 & 6.56 & 6.8 \\
5 & 94.6 & 96.6 & 100.0 & 97.1 & 2.73 & 2.8 \\
10 & 87.3 & 88.6 & 89.7 & 88.5 & 1.20 & 1.4 \\
20 & 99.2 & 83.5 & 88.3 & 90.3 & 8.05 & 8.9
\end{tabular}

${ }^{a}$ Replicates. ${ }^{b}$ Standard deviation. ${ }^{c}$ Coefficient of variance.

a pearling machine. An appropriate amount of ergosterol in chloroform was added to each $200 \mathrm{mg}$ of ground ergosterolfree barley, and the spiked samples were dried in a hood for 2 h. The percent recovery of ergosterol from ground barley was evaluated at five concentration levels, i.e., $0.2,1,5,10$, and 20 $\mu \mathrm{g} / \mathrm{g}$ (ppm), and with three replicates of each concentration. The results showed that the recoveries at the five concentration levels were 96.6, 97.1, 97.1, 88.5, and 90.3\% with the coefficient of variation $(\mathrm{CV})$ of $3.6,6.8,2.8,1.4$, and $8.9 \%$, respectively (Table 1). The excellent recoveries of ergosterol suggested that "one step" hexane extraction is sufficient as compared with the traditional "three step" extraction used by Lamper et al. (20). This "one step" process simplified the extraction procedure, saved solvent and materials used for sample extraction, and saved workers' time for sample preparation, which sped up the process of sample preparation and reduced the cost of ergosterol analysis.

To examine interferences from hull components, we spiked $200 \mathrm{mg}$ of ground barley samples (cultivar Robust, Arizona) without removing hulls with 200 and 1000 ng of ergosterol, respectively. Three replicates were used for each concentration. The ergosterol recoveries of $93.3(\mathrm{CV}, 2.0 \%)$ and $92.9 \%(\mathrm{CV}$, $2.2 \%$ ) were obtained at the two concentration levels with the consideration of a small amount of ergosterol preexisted in the seeds. The values are comparable with those from the spiked hulless barley samples (Table 1), which indicate that components from barley hulls do not interfere with the ergosterol analysis.

The percent recovery of ergosterol from a single kernel was evaluated in the following manner due to the difficulty of evenly spiking a hard kernel with ergosterol (23). Each of seven wheat kernels was saponified with $5 \% \mathrm{KOH}(\mathrm{w} / \mathrm{v})$ in $\mathrm{MeOH} / \mathrm{H}_{2} \mathrm{O}(95 /$ $5, \mathrm{v} / \mathrm{v})$ at $80{ }^{\circ} \mathrm{C}$ for $6 \mathrm{~h}$ and then at room temperature for $18 \mathrm{~h}$. 
Table 2. Percent Recovery of Ergosterol from Single Wheat Kernels

\begin{tabular}{lllll}
\hline & \multicolumn{4}{c}{ Erg $_{\text {kernel }}{ }^{i}(\mathrm{ng})^{a}$} \\
\cline { 2 - 5 } kernel $(\mathrm{l})$ & expt 1 & \multicolumn{1}{c}{ expt 2 } & expt 3 & expt 4 \\
\hline 1 & 339.6 & 66.87 & 164.23 & 135.89 \\
2 & 92.69 & 258.59 & 221.33 & 73.57 \\
3 & 88.50 & 346.4 & 179.76 & 42.21 \\
4 & 54.02 & 99.97 & 81.54 & 148.33 \\
5 & 44.44 & 178.39 & 145.31 & 58.68 \\
6 & 131.62 & 158.51 & 201.18 & 215.36 \\
7 & 311.83 & 46.32 & 339.00 & 133.35 \\
Erg $_{7 \text { kernels }}(\mathrm{ng})^{b}$ & 1062.7 & 1155.05 & 1332.35 & 807.39 \\
Ergresidue $^{\text {(ng) }}{ }^{c}$ & 45.72 & 58.89 & 57.86 & 60.73 \\
recovery $(\%)^{d}$ & 95.9 & 95.1 & 95.8 & 93.0
\end{tabular}

${ }^{a}$ Amount of ergosterol in each kernel $(I)$ determined using the method for a single kernel. ${ }^{b}$ The sum of ergosterol in seven kernels $\left(\right.$ Erg $_{7 \text { Kernels }}=$ $\left.\sum_{i=1}^{7} E \operatorname{crg}_{\text {kernel }}\right)^{j} .{ }^{c}$ Residual ergosterol in seven kernels after single kernel extraction. ${ }^{d}$ Percent recovery $=\left[\operatorname{Erg}_{7 k \text { kernels }}\left(\operatorname{Erg}_{7 \text { kernels }}+\right.\right.$ Ergresidue $\left.)\right] \times 100$.

Ergosterol in each kernel ( $\operatorname{Erg}_{\text {kernel }}{ }^{i}$, where $i$ is the kernel number) was extracted, derivatized, and analyzed using the procedures for a single kernel. To analyze amount of residual ergosterol in the kernels, seven extracted kernels were combined, rinsed with water, and dried in a hood overnight. The kernels were ground with mortar and pestle, and the residual ergosterol (Erg residue $_{\text {) }}$ was analyzed by the method used for ground samples. The percent recovery from single kernels was calculated with the following equation: recovery $\%=\left[\operatorname{Erg}_{7 \text { kernels }} /\left(\operatorname{Erg}_{7 \mathrm{kernels}}+\right.\right.$ $\left.\left.\operatorname{Erg}_{\text {residue }}\right)\right] \times 100$, where $\operatorname{Erg}_{7 \text { kernels }}$ is the sum of ergosterol in seven kernels $\left(\operatorname{Erg}_{7 \mathrm{kernels}}=\sum_{i=1}{ }^{7} \operatorname{Erg}_{\text {kernel }}{ }^{i}\right)$. The experiments were repeated four times on four different days. As shown in Table 2, the extraction recoveries of ergosterol from single kernels were between 93.0 and $95.9 \%$.

To evaluate the stability of ergosterol under the single kernel extraction condition, $200 \mathrm{mg}$ of ground ergosterol-free barley samples was spiked with ergosterol at 1 and 5 ppm concentration levels with three replicates for each concentration. The spiked samples were saponified with $5 \% \mathrm{KOH}(\mathrm{w} / \mathrm{v})$ in $\mathrm{MeOH} / \mathrm{H}_{2} \mathrm{O}$ $(95 / 5, \mathrm{v} / \mathrm{v})$ at $80^{\circ} \mathrm{C}$ for $6 \mathrm{~h}$ and then at room temperature for $18 \mathrm{~h}$. The cap was loosened to release internal pressure around 5 min after heating and then retightened. Ergosterol was extracted, derivatized, and analyzed as described for ground samples. The recoveries of ergosterol were $95.6 \%(\mathrm{CV}, 3.7 \%)$ and $92.9 \%(\mathrm{CV}, 1.4 \%)$ at the 1 and 5 ppm concentration levels, demonstrating the stability of ergosterol under the single kernel extraction condition.

The precision of the method was evaluated by analyzing 15 ground barley samples infected with Fusarium on three different days. On each day, the 15 samples were weighed, saponified, extracted, derivatized, and analyzed using the procedures for ground samples as described above. As shown in Table 3, the coefficient of variance for the method is in the range $0.8-12.3 \%$, indicating a high precision of the method. The precision of the method is comparable to the precision of $4-12 \%$ in a GC-MS method using a deuterated ergosterol $\left(\left[4{ }^{-2} \mathrm{H}_{2}\right]\right.$ ergosterol $)$ as an internal standard (8).

The method detection limit (MDL) and the method quantification limits (MQL) for analyzing ergosterol in barley samples were determined using the two-step approach involving the rmse method (rmse $=$ root-mean-square error) and the $t_{99(n-1)} S_{\mathrm{ELOQ}}$ method $\left[t_{99(n-1)}=\right.$ "one-tailed $t$-statistic" for $n-1$ observations at the $99 \%$ confidence level; $S_{\mathrm{ELOQ}}=$ standard deviation of measurements for the estimated limit of quantification (ELOQ)] described by Johannes Corley (24). Briefly, a five-point calibration curve with ergosterol concentrations within 1 order
Table 3. Precision of the Method for the Analysis of Ergosterol (Erg) in Barley Samples

\begin{tabular}{|c|c|c|c|c|c|c|}
\hline \multirow[b]{2}{*}{ sample } & \multicolumn{4}{|c|}{$\operatorname{Erg}(\mu \mathrm{g} / \mathrm{g})$} & \multirow[b]{2}{*}{$\mathrm{SD}^{a}$} & \multirow[b]{2}{*}{$\% C V^{b}$} \\
\hline & day 1 & day 2 & day 3 & $\overline{\text { mean }}$ & & \\
\hline 1 & 17.63 & 15.70 & 16.57 & 16.63 & 0.97 & 5.8 \\
\hline 2 & 8.63 & 7.30 & 8.11 & 8.01 & 0.67 & 8.4 \\
\hline 3 & 14.47 & 15.24 & 17.42 & 15.71 & 1.53 & 9.7 \\
\hline 4 & 10.68 & 11.29 & 10.05 & 10.67 & 0.62 & 5.8 \\
\hline 5 & 4.08 & 4.01 & 4.20 & 4.10 & 0.10 & 2.3 \\
\hline 6 & 6.49 & 7.08 & 7.15 & 6.91 & 0.36 & 5.3 \\
\hline 7 & 24.35 & 24.84 & 22.62 & 23.94 & 1.17 & 4.9 \\
\hline 8 & 14.60 & 12.86 & 13.63 & 13.70 & 0.87 & 6.4 \\
\hline 9 & 67.05 & 61.95 & 74.24 & 67.75 & 6.17 & 9.1 \\
\hline 10 & 10.66 & 10.36 & 12.68 & 11.23 & 1.26 & 11.2 \\
\hline 11 & 29.36 & 22.98 & 27.40 & 26.58 & 3.27 & 12.3 \\
\hline 12 & 21.30 & 21.57 & 21.26 & 21.38 & 0.17 & 0.8 \\
\hline 13 & 19.71 & 17.93 & 19.98 & 19.21 & 1.11 & 5.8 \\
\hline 14 & 36.52 & 36.60 & 40.65 & 37.92 & 2.36 & 6.2 \\
\hline 15 & 0.21 & 0.18 & 0.20 & 0.20 & 0.02 & 7.8 \\
\hline
\end{tabular}

${ }^{a}$ Standard deviation. ${ }^{b}$ Coefficient of variance.

of magnitude of the estimated detection limit was constructed in barley matrix. The rmse method was used to calculate the instrumental quantification limit (IQL), and the ELOQ of the method was, subsequently, obtained on the basis of IQL taking into consideration extraction recovery and dilution factors for the extraction procedure. Seven $200 \mathrm{mg}$ of ergosterol-free barley samples were fortified with appropriate amount of ergosterol so that the final concentration of ergosterol in barley equals the ELOQ. The fortified samples were extracted and analyzed using the method for ground samples. The MDL and MQL for detecting ergsterol in barley were 18.5 and $55.6 \mathrm{ng} / \mathrm{g}$, respectively, as calculated by the $t_{99(n-1)} S_{\text {ELOQ }}$ method. The validity of the calculated MDL was confirmed by analyzing three ergosterol-free barley samples fortified with ergosterol at the MDL level. A well-defined characteristic peak of ergosterol at $\mathrm{m} / \mathrm{z} 363$ was observed with a $\mathrm{S} / \mathrm{N}$ of 7 , indicating that the calculated MDL value was reasonable.

In conclusion, a rapid, sensitive, and reliable GC-MS method for analyzing ergosterol in barley and wheat has been developed. The method has been validated, and it has high accuracy and precision as well as low detection limit (18.5 ng/g) and quantification limit $(55.6 \mathrm{ng} / \mathrm{g})$. The method has several advantages. "One step" ergosterol extraction together with a simple and more efficient TMSI/TMCS silylating procedure greatly speeds up the process of sample preparation and makes it possible for one person to process 80 samples/day. This rapid and high throughput method may facilitate studies on screening cereal cultivars for resistance to FHB. The method can be used to analyze ergosterol in a single kernel, which provides a tool to investigate early fungal invasion, monitor fungal growth, and study mechanisms of resistance to FHB and other fungal diseases in greenhouses and laboratories where materials are limited most of the time. The GC-MS method provides an extra tool in addition to HPLC methods to combat fungal disease in grains.

\section{LITERATURE CITED}

(1) Leonard, K. J., Bushnell, W. R., Eds. Fusarium Head Blight of Wheat and Barley; APS Press: St. Paul, MN, 2003.

(2) Nganje, W. E.; Kaitibie, S.; Wilson, W. W.; Leistritz, F. L.; Bangsund, D. A. Economic Impacts of Fusarium Head Blight in Wheat and Barley: 1993-2001. Agribus. Appl. Econ. Rep. 2004, No. 538 . 
(3) Weete, J. D. Lipid Biochemistry of Fungi and Other Organisms; Plenum Press: New York, 1980.

(4) Seitz, L. M.; Sauer, D. B.; Burroughs, R.; Mohr, H. E.; Hubbard, J. D. Ergosterol as a measure of fungal growth. Phytopathology 1979, 69, 1202-1203.

(5) Young, J. C. Microwave-assisted extraction of the fungal metabolite ergosterol and total fatty acids. J. Agric. Food Chem. 1995, 43, 2904-2910.

(6) Axelsson, B. O.; Saraf, A.; Larsson, L. Determination of ergosterol in organic dust by gas chromatography-mass spectrometry. J. Chromatogr., B 1995, 666, 77-84.

(7) Saraf, A.; Larsson, L.; Burge, H.; Milton, D. Quantification of ergosterol and 3-hydroxy fatty acids in settled house dust by gas chromatography-mass spectrometry: comparison with fungal culture and determination of endotoxin by a Limulus amebocyte lysate assay. Appl. Environ. Microbiol. 1997, 63, 2554-2559.

(8) Nielsen, K. F.; Madsen, J. $\varnothing$. Determination of ergosterol on mouldy building materials using isotope dilution and gas chromatography-tandem mass spectrometry. J. Chromatogr., A 2000, 898, 227-234.

(9) Pasanen, A.; Yli-Pietilä, K.; Pasanen, P.; Kalliokoski, P.; Tarhanen, J. Ergosterol content in various fungal species and biocontaminated building materials. Appl. Environ. Microbiol. 1999, 65, 138-142.

(10) West, A. W.; Grant, W. D.; Sparling, G. P. Use of ergosterol, diaminopimelic acid and glucosamine contents of soils to monitor changes in microbial populations. Soil Biol. Biochem. 1987, 19, 607-612.

(11) Ravelet, C.; Grosset, C.; Alary, J. Quantitation of ergosterol in river sediment by liquid chromatography. J. Chromatogr. Sci. 2001, 39, 239-242.

(12) Gessner, M. O.; Schmitt, A. L. Use of solid-phase extraction to determine ergosterol concentrations in plant tissue colonized by fungi. Appl. Environ. Microbiol. 1996, 62, 415-419.

(13) Volker, E. J.; Dilella, D.; Terneus, K.; Baldwin, C.; Volker, I. The determination of ergosterol in environmental samples. $J$. Chem. Educ. 2000, 77, 1621-1623.

(14) Reid, L. M.; Nicol, R. W.; Ouellet, T.; Savard, M.; Miller, J. D.; Young, J. C.; Stewart, D. W.; Schaafsma, A. W. Interaction of Fusarium graminearum and F. moniliforme in Maize Ears: Disease Progress, Fungal Biomass, and Mycotoxin Accumulation. Phytopathology 1999, 89, 1028-1037.
(15) Wanyoike, M. W.; Walker, F.; Buchenauer, H. Relationship between virulence, fungal biomass and mycotoxin production by Fusarium graminearum in winter wheat head blight. J. Plant Dis. Prot. 2002, 109, 589-600.

(16) Dorofeev, D. A.; Artemenko, E. N.; Devyatkina, G. A. Optimizing the method of determining Fusarium spp. biomass based on ergosterol content. Russ. Agric. Sci. 2002, 10-13.

(17) Seitz, L. M.; Mohr, H. E.; Burroughs, R.; Sauer, D. B. Ergosterol as an indicator of fungal invasion in grains. Cereal Chem. 1977, $54,1207-1217$.

(18) Miller, J. D.; Young, J. C.; Sampson, D. R. Deoxynivalenol and Fusarium head blight resistance in spring cereals. Phytopath. $Z$. 1985, 113, 359-367.

(19) Snijders, C. H. A.; Krechting, C. F. Inhibition of deoxynivalenol translocation and fungal colonization in Fusarium head blight resistant wheat. Can. J. Bot. 1992, 70, 1570-1576.

(20) Lamper, C.; Téren, J.; Bartók, T.; Komoróczy, R.; Mesterházy, Á.; Sági, F. Predicting DON contamination in Fusarium-infected wheat grains via determination of the ergosterol content. Cereal Res. Commun. 2000, 28, 337-344.

(21) Miller, J. D.; Young, J. C.; Trenholm, H. L. Fusarium toxins in field corn. I. Time course of fungal growth and production of deoxynivalenol and other mycotoxins. Can. J. Bot. 1983, 61, 3080-3087.

(22) Schwadorf, K.; Mueller, H. M. Determination of ergosterol in cereals, mixed feed components, and mixed feeds by liquid chromatography. J. Assoc. Off. Anal. Chem. 1989, 72, 457-62.

(23) Mirocha, C. J.; Kolaczkowski, E.; Xie, W.; Yu, H.; Jelen, H. Analysis of deoxynivalenol and its derivatives (batch and single kernel) using gas chromatography/mass spectrometry. J. Agric. Food Chem. 1998, 46, 1414-1418.

(24) Corley, J. Best practices in establishing detection and quantification limits for pesticide residues in foods. In Handbook of Residue Analytical Methods for Agrochemicals; Lee, P. W., Ed.; John Wiley \& Sons Ltd.: Hoboken, NJ, 2003; Vol. 1-2, pp $59-75$.

Received for review January 18, 2006. Revised manuscript received April 10, 2006. Accepted April 12, 2006. The authors thank the financial supports from the Minnesota Small Grains Initiative and the U.S. Wheat and Barley Scab Initiative.

JF060149F 